\section{(6) OPEN ACCESS}

\title{
Defocus Incorporated Soft Contact (DISC) lens slows myopia progression in Hong Kong Chinese schoolchildren: a 2-year randomised clinical trial
}

\author{
Carly Siu Yin Lam, ${ }^{1}$ Wing Chun Tang, ${ }^{1}$ Dennis Yan-Yin Tse, ${ }^{1,2}$ Ying Yung Tang, ${ }^{1}$ \\ Chi Ho To ${ }^{1,3}$
}

${ }^{1}$ Centre for Myopia Research School of Optometry, The Hong Kong Polytechnic University, Hung Hom, Kowloon, Hong Kong. ${ }^{2}$ Department of Ophthalmology, Cullen Eye Institute, Baylor College of Medicine, Houston

${ }^{3}$ State Key Laboratory of Ophthalmology, Zhongshan Ophthalmic Centre, Sun Yat Sen University, Guangzhou, China

\section{Correspondence to} Professor Carly SY Lam, Centre for Myopia Research, School of Optometry, The Hong Kong Polytechnic University, Hung Hom, Kowloon, Hong Kong; carly.lam@polyu.edu.hk

Received 28 June 2013 Revised 12 September 2013 Accepted 10 October 2013 Published Online First 29 October 2013

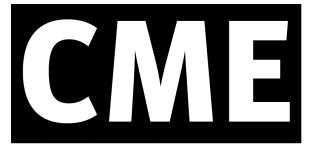

OFollow the link from the online version of this article to obtain certified continuing medical education credits

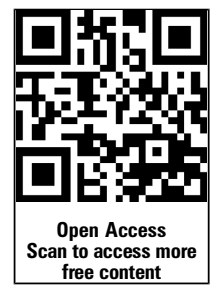

To cite: Lam CSY, Tang WC, Tse DY-Y, et al. $\mathrm{Br} J$ Ophthalmol 2014;98:40-45.

\section{ABSTRACT}

Aims To determine if 'Defocus Incorporated Soft Contact' (DISC) lens wear slows childhood myopia progression.

Methods A 2-year double-blind randomised controlled trial was carried out in 221 children aged 8-13 years, with myopia between -1.00 and -5.00 Dioptres (D) and astigmatism $\leq 1.00 \mathrm{D}$. Subjects were randomly assigned to the DISC $(n=111)$ or single vision (SV; $n=110$ ) contact lens group. DISC lenses incorporated concentric rings, which provided an addition of $+2.50 \mathrm{D}$, alternating with the normal distance correction. Refractive error (cycloplegic autorefraction) and axial length were measured at 6-month intervals. Differences between groups were analysed using unpaired $t$ test. Results In total, 128 children completed the study, $n=65$ in the DISC group and $n=63$ in the SV group. Myopia progressed $25 \%$ more slowly for children in the DISC group compared with those in the control group $(0.30 \mathrm{D} /$ year; $95 \% \mathrm{Cl}-0.71$ to -0.47 vs 0.4 D/year; $95 \% \mathrm{Cl}-0.93$ to $-0.65, p=0.031)$. Likewise, there was less axial elongation for children in the DISC versus SV groups $(0.13 \mathrm{~mm} / \mathrm{year} ; 95 \% \mathrm{Cl} 0.20$ to $0.31 \mathrm{vs}$ $0.18 \mathrm{~mm} /$ year; $95 \% \mathrm{Cl} 0.30$ to $0.43, p=0.009$ ). Treatment effect correlated positively with DISC lens wearing time $(r=0.342 ; p=0.005)$. Indeed, myopia in children who wore the DISC lenses for five or more hours/day progressed $46 \%$ (mean difference $=-0.382 \mathrm{D}$, $\mathrm{p}=0.001 ; 95 \% \mathrm{Cl}-0.59$ to -0.17 ) less than those in the SV group.

Conclusions The daily wearing of DISC lens significantly slowed myopia progression and axial elongation in Hong Kong schoolchildren. The findings demonstrated that simultaneous clear vision with constant myopic defocus can retard myopia progression.

\section{INTRODUCTION}

The prevalence of myopia is especially high in Asian urban regions. Myopia starts commonly when children enter school at the age of 5-6 years, and as many as $80 \%$ of teenagers are myopic. ${ }^{1-3}$ Myopic eyes are prone to a number of ocular pathologies, such as retinal degeneration and glaucoma, ${ }^{45}$ which can lead to severe visual impairment. Its impact on public health and economy is becoming very enormous.

A variety of strategies with optical devices has been used in an attempt to slow myopia progression in children. Progressive addition lenses (PALs) have shown insignificant effect on myopia control, ${ }^{6-11}$ and bifocal spectacle lenses have shown promising effect on children with fast myopia progression. ${ }^{12}$
Orthokeratology has showed certain effect on retarding axial elongation, ${ }^{13}{ }^{14}$ but children need to sleep with lenses overnight to maintain appropriate corneal curvature and clear vision.

Emmetropisation is a process describing how an eye is growing to the refractive state where distant objects are focused on the retina without accommodation. This process is widely known to be visually guided. ${ }^{15}$ Retinal defocus can be introduced by lenses experimentally so as to change emmetropisation and hence refractive status in young animals. Chick studies have showed myopic eye growth was reduced by incorporating myopic defocus simultaneously with dual-power lenses. ${ }^{16}{ }^{17}$ Based on these findings, we hypothesised emmetropisation in human eyes is regulated by an equilibrium between the opposite hyperopic and myopic defocus. Refractive errors result from disruption of this equilibrium: insufficient ambient myopic defocus may promote myopia and excessive myopic defocus may promote hyperopia. The design of the Defocus Incorporated Soft Contact (DISC) lens applies concentric alternating distance correcting and defocusing zones covering the pupil. The correcting zones provide clear vision, and the defocusing zones simultaneously incorporate constant myopic defocus on the retina. The aim of the study was to determine whether wearing DISC lens could slow myopia progression in schoolchildren with myopia.

\section{MATERIALS AND METHODS Subjects}

Hong Kong Chinese children $(n=221)$ were recruited and participated in this trial. The first and the last subjects were recruited in September 2007 and October 2009, respectively. Inclusion criteria were:

- Age at enrolment: 8-13 years

- Spherical equivalent refractions (SERs): -1.00 to -5.00 Dioptres (D)

- Astigmatism: 1.00 D or less

- Anisometropia: $1.25 \mathrm{D}$ or less

- Spectacle corrected monocular visual acuity (VA): $0.0 \log$ MAR or better

- Contact lens corrected monocular VA: 0.1 logMAR or better

- Free of ocular and systemic abnormalities might affect visual functions or refractive development

- No prior use of PALs, bifocal contact lenses

- No contraindication for contact lens wear

- Willingness to wear contact lenses regularly

- Parents' understanding and acceptance of random allocation of grouping 
We sought $90 \%$ power to detect $0.50 \mathrm{D}$ difference (with $0.7 \mathrm{D}$ of SD) ${ }^{6}$ in myopia progression between two groups with a significance $\alpha$ level of 0.01 (two-tailed); the minimum subject number required in each group was 59.

\section{Study design}

This was a prospective, randomised and double-masked study. The children were randomly allocated to wear either DISC lenses or single vision (SV) contact lenses. Allocation was determined by a random software sequence in ex-cell. Their cycloplegic refraction and axial length (AXL) were followed up every 6 months over 2 years. The change in refraction and AXL in children between the two groups were compared. Data collection was performed at the Centre for Myopia Research, the Hong Kong Polytechnic University (PolyU). All procedures met the tenets of the Declaration of Helsinki and were approved by the Human Subjects Ethics Subcommittee of PolyU. Written consent was obtained from children and parents before participation.

The study design was similar to that in our study using PALs. ${ }^{6}$ One investigator was masked from grouping and was responsible for refracting and relevant ocular data measurement. The other investigator was unmasked and responsible for group allocation, lens fitting and aftercare, measuring lens performance, record keeping and compliance checking. The children and their parents were not told which lens design was prescribed. The masking procedures fulfilled the Consolidated Standards of Reporting Trials requirements for a double-masked trial. ${ }^{18}$

\section{Contact lenses}

DISC lens was a custom-made bifocal soft contact lens of concentric rings design. It comprised of a correction zone in the centre and a series of alternating defocusing and correction zones extending towards the periphery having a proportion of 50:50. The correcting zones matched the distant prescription while the defocusing zones were $2.5 \mathrm{D}$ relatively negative. Such design allowed to introduce myopic retinal defocus and to maintain clear vision, simultaneously. The lenses were lathe-cut from 2-hydroxyethyl methacrylate, with $38 \%$ water content, base curve between $8.0-8.9 \mathrm{~mm}$ and lens diameter of $13.5 \mathrm{~mm}$ or $14.0 \mathrm{~mm}$. The SV lenses were made using the same material with matching parameters without any defocusing zones. All lenses for left eyes were blue-tinted to prevent lens swapping.

Contact lens fitting was performed according to cycloplegic refraction, corneal curvature and horizontal visible iris diameter. Adjustments to the final prescription were based on spherical over-refraction. Regular aftercare was scheduled and contact lenses were replaced after each 6-month data collection visit, and if over-refraction was more than $0.5 \mathrm{D}$. Distance and near VA were measured with Logarithmic 2000 series Early Treatment Diabetic Retinopathy Study (ETDRS) Chart at $4 \mathrm{~m}$ (Precision Vision) and Near Vision Test Card by PolyU, respectively.

The children were recommended to wear lenses for 5-10 h/ day and requested to wear full spectacles prescription after contact lens wear. Log sheets were given for recording lens wearing time every day. The average wearing hours/day was calculated (total wearing hours/total number of days during the study) as a reference of compliance. In consideration of adaptation issue, wearing hours of the 1st month were excluded. Subjects who were contraindicated to continue contact lens wear (eg, poor external ocular health or compliance) were excluded.

\section{Primary outcomes}

Refraction and AXL under cycloplegia were measured at baseline and at 6-month intervals for 2 years. One drop of proparacaine $0.4 \%$ and then $1-2$ drops of cyclopentolate HCL $1 \%$ were instilled to induce cycloplegia. Refraction was measured by using a Shin-Nippon NVision-K 5001 autorefractor. Ten measurements were obtained for each eye and the average of 10 SER was used for statistical analysis. AXL was measured by IOL Master (Carl Zeiss). Five measurements were taken and averaged.

\section{Other measurements}

Corneal curvature was measured by Medmont E300 Corneal Topographer before cycloplegia. Amplitude of accommodation with full spectacle correction and contact lenses was measured using the push-up method with Royal Air Force (RAF) ruler. Pupil images were captured using EAS-1000 (Nidek) when the subjects were wearing lenses. This allowed the correcting and myopic defocusing zones of DISC lenses covering the pupil to be observed. Pupil sizes under photopic $\left(80 \mathrm{~cd} / \mathrm{m}^{2}\right)$ and mesopic $\left(3 \mathrm{~cd} / \mathrm{m}^{2}\right)$ conditions were measured with the software $\mathrm{V} .1 .23 \mathrm{e}$ of EAS-1000.

\section{Statistical analysis}

There were no statistically significant differences between data from two eyes, only data of right eyes were used for analyses. Mann-Whitney $U$ tests and unpaired $t$ tests were used to compare baseline characteristics between the two groups. Myopia progression over 2 years was calculated as the difference between SER at the fifth and the first visits. The changes in SER and AXL between the two groups were compared using unpaired t test. Welch correction was applied if the difference of SD between the groups was statistically significant. Subgroup analysis with different cut-off of wearing hours/day was performed. Repeated-measures analysis of variance tests were used to compare changes in SER during the study period. Factors affecting myopia progression including initial age, gender, initial myopia and lens wearing time were investigated using multiple linear regression analysis. The efficacy of myopic control of DISC lens was determined by dividing the difference in the mean SER changes of the two groups by the mean SER change in the SV group, and then multiplying the result by $100 \%$.

\section{RESULTS}

\section{Baseline measures}

Table 1 shows the baseline characteristics of all subjects who were randomly allocated to the DISC and the SV groups. There were no statistically significant differences between the two groups in relation to age, gender proportion, SER, AXL and corneal power $(\mathrm{p}>0.33)$. The mean distance and near VA with both lens types were not significantly different $(p>0.45)$. Figure 1 shows the number of subjects and dropouts at different stages. One hundred and twenty-eight children completed the 2-year study (DISC, $\mathrm{n}=65$ vs SV, $\mathrm{n}=63$ ). The number of dropouts in the two groups was very similar.

\section{All completed subjects \\ Change in SER}

Over 2 years, the mean myopia progression for the DISC group and the SV group were $0.59 \pm 0.49 \mathrm{D}$ and $0.79 \pm 0.56 \mathrm{D}$, respectively. The DISC group showed significantly less myopia progression than the SV group (mean difference $=-0.20$, $\mathrm{p}=0.031$ ) by $25 \%$. The mean myopia progressions in the two 
Table 1 Baseline demographics data $($ mean \pm SD) of all subjects $(n=221)$ in the DISC and the SV groups

\begin{tabular}{|c|c|c|c|c|c|c|}
\hline & \multicolumn{2}{|l|}{ All } & \multicolumn{2}{|l|}{ Completed } & \multicolumn{2}{|l|}{ Dropout } \\
\hline & $\operatorname{DISC}(n=111)$ & SV $(n=110)$ & DISC $(n=65)$ & SV $(n=63)$ & DISC $(n=46)$ & SV $(n=47)$ \\
\hline Age (years) & $11.01 \pm 1.48$ & $10.85 \pm 1.62$ & $11.06 \pm 1.55$ & $10.87 \pm 1.67$ & $11.05 \pm 1.49$ & $10.84 \pm 1.60$ \\
\hline Gender (female: male) & $72: 39$ & $64: 46$ & $44: 21$ & $39: 24$ & $28: 18$ & $25: 22$ \\
\hline Cycloplegic autorefraction in SER (D) & $-2.86 \pm 1.02$ & $-2.79 \pm 1.06$ & $-2.90 \pm 1.05$ & $-2.80 \pm 1.03$ & $-2.85 \pm 1.12$ & $-2.80 \pm 1.07$ \\
\hline Axial length $(\mathrm{mm})$ & $24.70 \pm 0.74$ & $24.65 \pm 0.78$ & $24.69 \pm 0.74$ & $24.62 \pm 0.79$ & $24.70 \pm 0.75$ & $24.65 \pm 0.74$ \\
\hline Corneal power for steep meridian (D) & $44.28 \pm 1.34$ & $44.14 \pm 1.37$ & $44.32 \pm 1.25$ & $44.30 \pm 1.22$ & $44.24 \pm 1.25$ & $44.12 \pm 1.36$ \\
\hline Corneal power for flat meridian (D) & $43.16 \pm 1.25$ & $43.02 \pm 1.38$ & $43.22 \pm 1.23$ & $43.14 \pm 1.27$ & $43.12 \pm 1.44$ & $43.07 \pm 1.36$ \\
\hline Distance VA with contact lenses (logMAR) & $-0.07 \pm 0.06$ & $-0.08 \pm 0.06$ & $-0.06 \pm 0.06$ & $-0.08 \pm 0.06$ & $-0.06 \pm 0.07$ & $-0.08 \pm 0.06$ \\
\hline Near VA with contact lenses (logMAR) & $-0.09 \pm 0.01$ & $-0.09 \pm 0.03$ & $-0.09 \pm 0.02$ & $-0.09 \pm 0.03$ & $-0.09 \pm 0.02$ & $-0.09 \pm 0.03$ \\
\hline
\end{tabular}

DISC, Defocus Incorporated Soft Contact; SER, spherical equivalent refraction; SV, single vision.

groups over 2 years are shown in figure $2 \mathrm{~A}$ and refractive statuses are provided in table 2 . The multiple linear regression analysis indicated lens wearing time $(p=0.02)$ was found to be a statistically significant effect on the change of SER in the DISC group and the coefficient of covariates was 0.06 .

\section{Change in $\mathrm{AXL}$}

A highly significant correlation was found between changes in SER and changes in AXL in DISC $(r=-0.70, \mathrm{p}<0.0001)$ and $\mathrm{SV}(\mathrm{r}=-0.68, \mathrm{p}<0.0001)$ groups. The total increase in AXL was $0.25 \pm 0.23 \mathrm{~mm}$ in the DISC group and $0.37 \pm 0.24 \mathrm{~mm}$ in the SV group. The AXL changes were consistent with the refractive findings, there was statistically significant difference between the two groups (mean difference $=0.11 \mathrm{~mm}, \mathrm{p}=0.009$ ). The mean AXL change in the two groups is shown in figure $2 \mathrm{~B}$ and further details of AXL are listed in table 2.

Accommodation and pupil sizes

The mean amplitudes of accommodation were $12.37 \pm 2.46 \mathrm{D}$ and $12.07 \pm 1.87 \mathrm{D}$ for DISC and SV lenses, respectively. The amplitudes of accommodation with DISC lenses was not significantly different $(p=0.875)$ from spectacles $(12.30 \pm 2.16 \mathrm{D})$.
Figure 1 Flow diagram of progress through the study. DISC, Defocus Incorporated Soft Contact; SV, single vision.

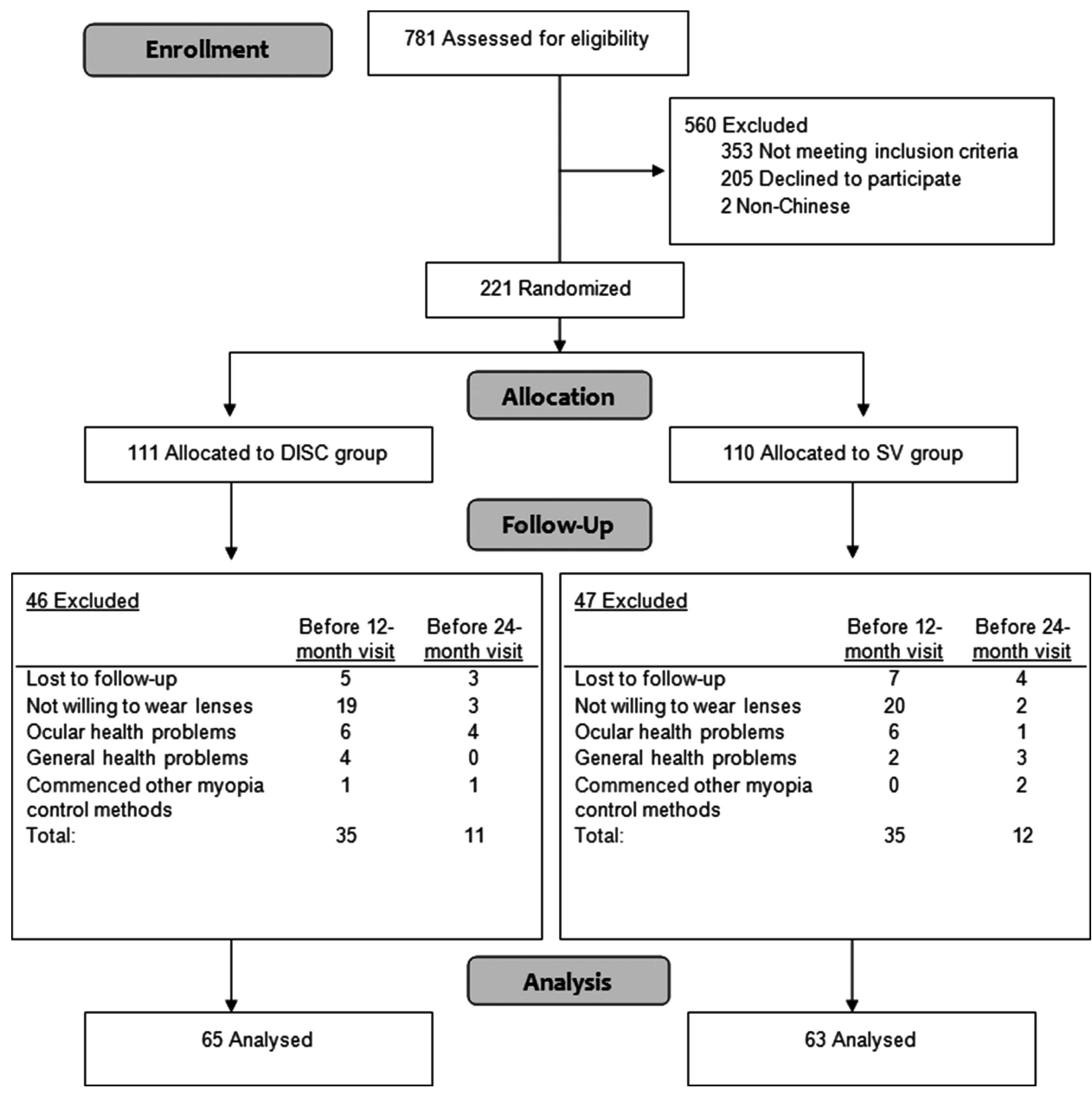



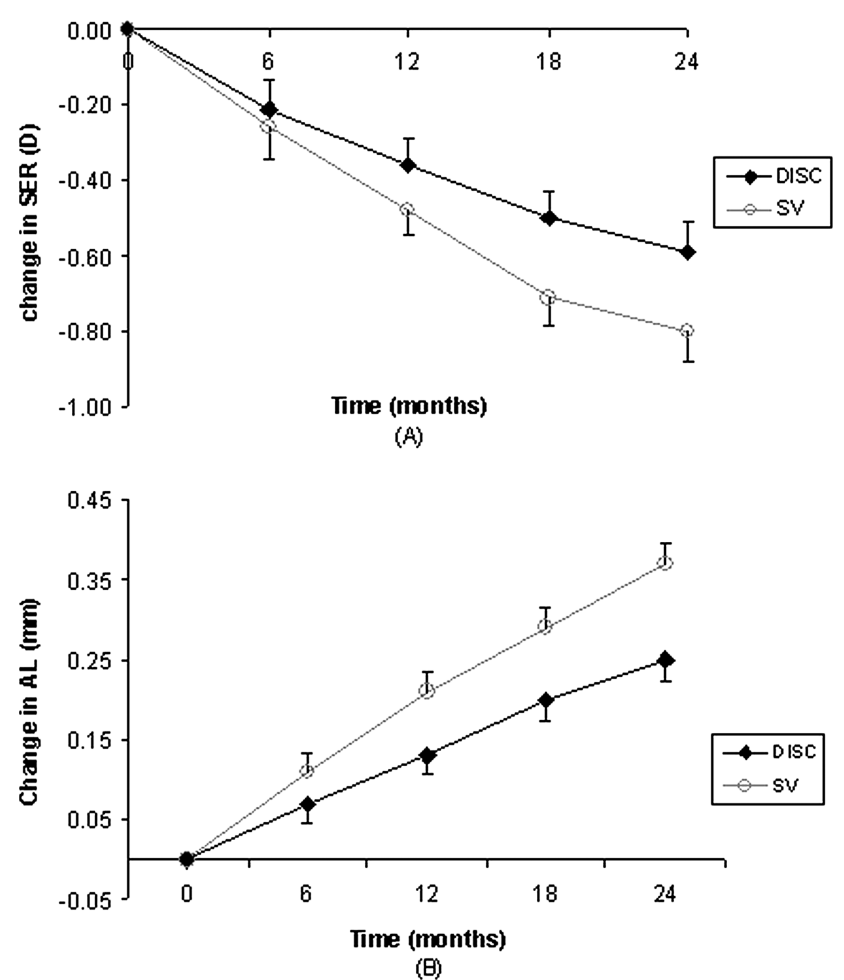

Figure 2 (A) Mean and SEM of myopia progression (spherical equivalent refractions) and (B) mean and SEM of axial length elongation for the subjects who completed the study. DISC, Defocus Incorporated Soft Contact; SV, single vision.

Children wearing DISC lenses could accommodate normally to near objects, and were less likely to use the defocusing zones for viewing during near tasks.

There was no statistically significant difference of pupil sizes between two groups under photopic $(p=0.078)$ and mesopic $(p=0.087)$ conditions. The mean pupil sizes of the children wearing DISC lenses were $5.07 \pm 0.80 \mathrm{~mm}$ and $6.79 \pm 0.70 \mathrm{~mm}$ under photopic and mesopic conditions, respectively. Pupil size was found to adequately cover correcting and defocusing zones.

Table 2 Changes (mean \pm SD) in cycloplegic autorefraction (SER) and axial length in subjects who completed the 2-year study at each visit

\begin{tabular}{lll}
\hline & DISC $(\mathrm{n}=65)$ & SV $(\mathrm{n}=63)$ \\
\hline $\begin{array}{l}\text { Cycloplegic autorefraction (D) } \\
\text { Baseline }\end{array}$ & $-2.90 \pm 1.05$ & \\
6 months & $-3.11 \pm 1.09$ & $-2.80 \pm 1.03$ \\
12 months & $-3.26 \pm 1.08$ & $-3.06 \pm 1.22$ \\
18 months & $-3.40 \pm 1.14$ & $-3.28 \pm 1.14$ \\
24 months & $-3.49 \pm 1.17$ & $-3.51 \pm 1.20$ \\
Axial length (mm) & & $-3.60 \pm 1.29$ \\
Baseline & $24.69 \pm 0.74$ & \\
6 months & $24.76 \pm 0.74$ & $24.62 \pm 0.79$ \\
12 months & $24.82 \pm 0.74$ & $24.73 \pm 0.82$ \\
18 months & $24.89 \pm 0.74$ & $24.83 \pm 0.84$ \\
24 months & $24.94 \pm 0.75$ & $24.91 \pm 0.87$ \\
\hline
\end{tabular}

DISC, Defocus Incorporated Soft Contact; SER, spherical equivalent refraction; SV, single vision.

\section{Myopic progression versus wearing time}

There was no significant difference in wearing time between the DISC $(6.46 \pm 2.16 \mathrm{~h} /$ day) and the SV groups $(6.30 \pm 1.65 \mathrm{~h} /$ day $)$ $(p=0.644)$. The correlation of myopia progression and lens wearing time is shown in figure 3. Myopia progression in the DISC group was inversely proportion to wearing time $(r=0.342, p=0.005)$ whereas no such effect was found in the SV group. Table 3 shows the differences of myopia progression between two groups from different cut-off of lens wearing time. The effect of slowing myopia progression became obvious when there was a minimum of $5 \mathrm{~h} /$ day with DISC lenses, and increased with daily wearing hours.

\section{DISCUSSION}

The present study showed children wearing DISC lenses had $25 \%$ less myopia progression and 31\% less axial elongation than those wearing SV lenses over 2 years. The rate of myopia progression was quite linear and no plateau effect was observed (figure 2A). Those results support our past animal and human studies in adopting myopic defocus as a means of interfering with ocular growth. ${ }^{17} 19$ The regression analysis showed wearing time was a contribution factor to retardation effect of myopia progression with DISC lenses. A better effect was showed when daily wearing hours increased (figure 3, table 3). A similar temporal dose-response relationship has been reported in animals which found the effect of defocus related to exposure time. $^{20}$ A certain effect of myopia control (46\%) could be achieved by wearing DISC lens for at least $5 \mathrm{~h} /$ day. The effect further increased to $58 \%$ when children had worn DISC lenses for $7 \mathrm{~h} /$ day or more. The marginal benefit from increased wearing was smaller when wearing time reached $8 \mathrm{~h}$. There was inadequate information about how much wearing time is needed until effect level-off. The oxygen transmissibility level (Dk) of lens material limited daily wearing time to $10 \mathrm{~h}$ in our study. Therefore, $7-8 \mathrm{~h} /$ day might be an optimal wearing time for the DISC lens to function.

Table 4 summarises recent clinical trials of myopia control using optical methods. DISC lens $(0.11 \mathrm{D} /$ year $)$ showed similar retardation effect on myopia progression as compared with PALs (0.07-0.18 D/year)..$^{6-11} \mathrm{~A}$ study using a combination of bifocal and base-in prism showed promising treatment effect $(55 \%)$ over 2 years in a preselected group with fast progressing myopia. ${ }^{12}$ Sankaridurg et $a l^{21}$ have demonstrated myopia progression was slowed by $34 \%$ in 1 year using a multifocal soft contact lens which was designed for reducing relative peripheral hyperopia. Anstice and Phillips demonstrated a better slowing effect $(37 \%)$ using a concentric bifocal soft contact lens having $2 \mathrm{D}$ myopic defocus in the cross-over study. ${ }^{22}$ Their results were consistent with the notion that myopic progression could be slowed by manipulating myopic defocus simultaneously. The present study proved myopic defocus could slow myopia progression in binocular viewing condition.

Variations in retardation effects of DISC lenses may be due to different retinal profile or peripheral refraction. It was a limitation of the study that the retinal curvature profile was not measured, and we assumed the myopic defocus induced was sufficient to cover most part of the retina. Hence if the retinal profile is very prolate (steepening toward the periphery), the source of myopic defocus at the periphery will be less and may end up as hyperopic defocus. As reported in the literature, a highly prolate shape is not common among myopic eyes. ${ }^{23}$ Certain amount of myopic defocus might still be imposed on 
Figure 3 Correlation between myopia progression (spherical equivalent refractions) and contact lens daily wearing time. DISC, Defocus Incorporated Soft Contact; SV, single vision.

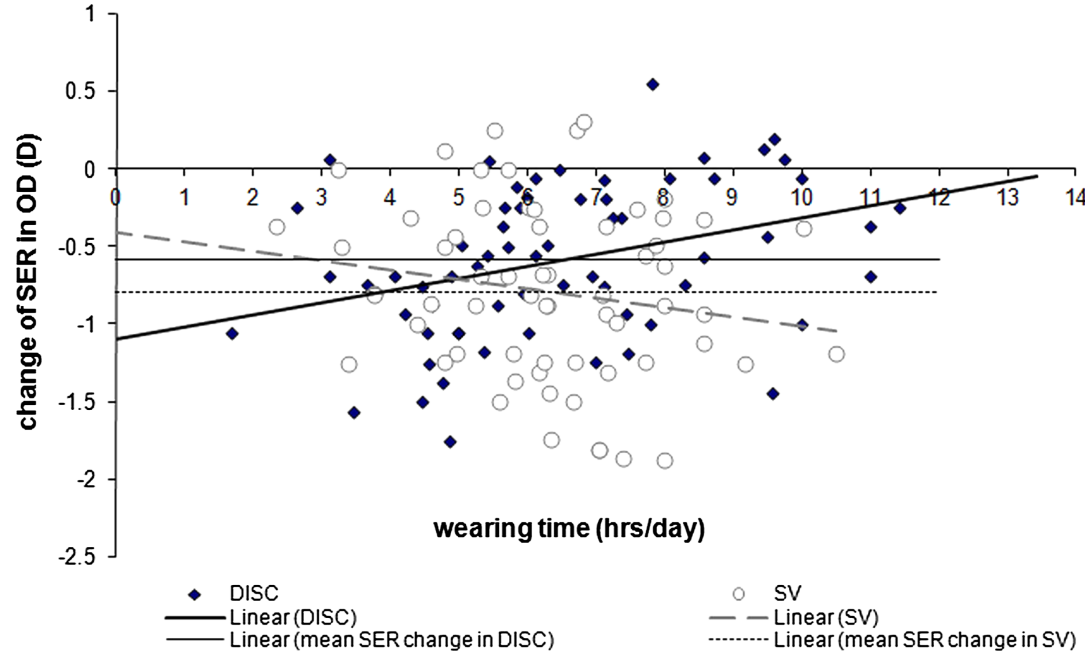

Table 3 The retardation effect of myopia progression from different cut-offs of lens wearing time

\begin{tabular}{lllll}
\hline Wearing time (hours/day) & Mean SER differences between two groups & $\mathbf{p}$ Value & $\%$ retardation of myopia progression & $\mathbf{9 5 \%} \mathbf{C l}$ \\
\hline All & 0.21 & 0.031 & 25 & -0.39 to -0.02 \\
4 or more & 0.23 & 0.019 & 28 & -0.42 to -0.04 \\
5 or more & 0.39 & 0.001 & 46 & -0.59 to -0.17 \\
6 or more & 0.44 & 0.001 & 50 & -0.69 to -0.20 \\
7 or more & 0.54 & 0.001 & 58 & -0.85 to -0.24 \\
8 or more & 0.53 & 0.014 & 60 & -0.94 to -0.12
\end{tabular}

SER, Spherical equivalent refraction.

Table 4 Clinical studies of myopia control in the past

\begin{tabular}{|c|c|c|c|c|c|c|c|}
\hline \multirow[b]{2}{*}{ Authors (years) } & \multirow[b]{2}{*}{$\begin{array}{l}\text { Period } \\
\text { (months) }\end{array}$} & \multirow[b]{2}{*}{ Design } & \multirow[b]{2}{*}{$\begin{array}{l}\text { Age (years old), } \\
\text { ethnicity }\end{array}$} & \multirow[b]{2}{*}{$\begin{array}{l}\text { Criteria of } \\
\operatorname{Rx}(D)\end{array}$} & \multirow[b]{2}{*}{$\begin{array}{l}\text { Interventions and } \\
\text { sample size (n) }\end{array}$} & \multicolumn{2}{|c|}{$\begin{array}{l}\text { Treatment effect in retarding } \\
\text { myopia progression }\end{array}$} \\
\hline & & & & & & $\begin{array}{l}\text { Study period } \\
\text { in } D(\%)\end{array}$ & $\begin{array}{l}\text { Per year } \\
\text { in } D\end{array}$ \\
\hline Present study & 24 & Randomised, masked & 8-13, Chinese & -1 to -5 . & $\begin{array}{l}\text { SV CL, } n=47 \\
\text { DISC, } n=49\end{array}$ & $0.21(25 \%)$ & 0.11 \\
\hline Edward et al $(2002)^{6}$ & 24 & Randomised, double masked & 7-10.5, Chinese & -1.25 to -4.5 & $\begin{array}{l}\text { SVL, } n=132 \\
\text { PAL (1.5 D Add), } n=121\end{array}$ & $0.14(11 \%)$ & 0.07 \\
\hline Gwiazda et al $(2003)^{7}$ & 36 & Randomised, masked & $\begin{array}{l}6-11 \text {, diverse } \\
\text { ethnicity }\end{array}$ & -1.25 to -4.5 & $\begin{array}{l}\text { SVL, } n=233 ; \\
\text { PAL (2 D Add), } n=229\end{array}$ & $0.20(14 \%)$ & 0.07 \\
\hline Hasebe et al (2008) ${ }^{8}$ & 18 & Randomised, masked, cross-over & 6-12, Japanese & -1.25 to -6 & $\begin{array}{l}\text { SVL, } n=44 ; \\
\operatorname{PAL}(1.5 \text { D Add), } n=42\end{array}$ & $\begin{array}{l}\text { 1st period: } 0.31 \\
(18 \%) \\
\text { 2nd period: } 0.02 \\
(2 \%)\end{array}$ & $\begin{array}{l}\text { 1st period: } \\
0.2 \\
\text { 2nd period: } \\
0.01\end{array}$ \\
\hline Yang et al (2009) ${ }^{9}$ & 24 & Randomised, masked & 7-13, Chinese & -0.5 to -3 & $\begin{array}{l}\text { SVL, } n=75 \\
\text { PAL(1.5 D Add), } n=74\end{array}$ & $0.26(17 \%)$ & 0.13 \\
\hline $\begin{array}{l}\text { COMET2 and PEDIG } \\
(2011)^{10}\end{array}$ & 36 & Randomised, masked, multicenter & $8-12$ & -0.75 to -2.50 & $\begin{array}{l}\text { SV, } n=58 \\
\operatorname{PAL}(2 \text { D Add), } n=52\end{array}$ & $0.28(24 \%)$ & 0.09 \\
\hline Berntsen et al $(2012)^{11}$ & 12 & $\begin{array}{l}\text { Randomised, masked, all worn SV in } \\
\text { 2nd year }\end{array}$ & $6-11$ & -0.75 to -4.50 & $\begin{array}{l}\text { SV, } n=42 \\
\operatorname{PAL}(2 \text { D Add), } n=41\end{array}$ & $0.18(35 \%)$ & 0.18 \\
\hline Cheng et al $(2010)^{12}$ & 24 & Randomised, masked & 8-13, Chinese & -1 to -5.5 & $\begin{array}{l}\text { SVL, } n=41 ; \\
\text { BF (1.5 D Add), } n=48 ; \\
\text { PBF (1.5 D Add, } 3 \Delta B I) \\
n=46\end{array}$ & $\begin{array}{l}\text { BF: } 0.59(38 \%) \\
\text { PBF: } 0.85(55 \%)\end{array}$ & $\begin{array}{l}\text { BF: } 0.3 \\
\text { PBF: } 0.43\end{array}$ \\
\hline $\begin{array}{l}\text { Anstice and Phillips } \\
(2011)^{22}\end{array}$ & 10 & $\begin{array}{l}\text { Randomised, paired-eye control, } \\
\text { cross-over }\end{array}$ & $\begin{array}{l}\text { 11-14, diverse } \\
\text { ethnicity }\end{array}$ & -1.25 to -4.5 & $\begin{array}{l}\text { SV CL, } n=40 \\
\text { DF (2 D MD), } n=40\end{array}$ & $\begin{array}{l}\text { 1st period: } 0.25 \\
(37 \%) \\
\text { 2nd period: } 0.2 \\
(54 \%)\end{array}$ & $\begin{array}{l}\text { 1st period: } \\
0.3 \\
\text { 2nd period: } \\
0.24\end{array}$ \\
\hline $\begin{array}{l}\text { Sankaridurg et al } \\
(2011)^{21}\end{array}$ & 12 & Randomised & 7-14, Chinese & -0.75 to -3.5 & $\begin{array}{l}\text { SVL, } \mathrm{n}=40 \\
\text { novel } \mathrm{CL}, \mathrm{n}=45\end{array}$ & $0.29(34 \%)$ & 0.29 \\
\hline
\end{tabular}

BF, bifocal spectacle lens; COMET2 and PEDIG, Correction of Myopia Evaluation Trial 2 Study Group and the Pediatric Eye Disease Investigator Group; DF, dual focus contact lens; DISC, Defocus Incorporated Soft Contact; MD, myopic defocus; PAL, progressive addition lens; PBF, prismatic bifocal lens; SV CL, single vision contact lens; SVL, single vision spectacle lens. 
peripheral retina with the use of $2.5 \mathrm{D}$ defocus, slowing myopia progression.

The other limitation was a high dropout rate ( 42\%). Three-fourths of the dropout occurred in the 1 st year. The main reason for both groups was lack of motivation in contact wear. Most of them wanted to wear contact lenses at the beginning in an attempt to slow myopia progression. They were unwilling to wear lenses every day afterwards because they were too busy with school curriculum and homework, and too rushed to wear lens in early morning. Some children quit because they refused to return for eye examination, especially with cycloplegia. A few children were excluded because of moderate papillae and recurrent corneal staining. Those children usually showed poor compliance, such as overworn lenses and improper lens care procedures. A small portion of the subjects were excluded due to allergic rhinitis. Most of the withdrawals were not willing to continue the follow-up. Complete data was not available for all randomised subjects. Statistical analysis on the completed cases and on a subgroup of children with longer wearing time introduces bias. Although the dropout rate was high, some children could successfully wear contact lenses, and adverse reactions were low.

In conclusion, myopia progression and axial elongation were slowed by wearing DISC lenses compared with SV lenses, reaching nearly $50 \%$ for those maintaining wearing time over $5 \mathrm{~h} /$ day. This prophylactic intervention is less invasive than those by pharmacological treatments, and has great potential for slowing myopia progression in children. Enhanced patient education may improve patient motivation, compliance and possibly treatment effect. The optimum amount of myopic defocus to arrive at stopping myopia progression is yet to be worked out; further investigation and lens customisation are needed. Improved contact lens material could further prolong safe wearing time, which may provide more flexibility to wearers and potentially increase exposure to defocus.

Acknowledgements The authors would like to thank Mr Edmund Chiang (Oxycon Contact Lenses, Hong Kong) for manufacturing contact lenses and AMO Asia for sponsorship of the contact lens care solutions.

Contributors CSYL designed data collection tools, monitored data collection for the whole trial, wrote the statistical analysis plan, cleaned and analysed the data, and drafted and revised the paper. She is guarantor. WCT implemented the trial, monitored data collection for the whole trial, analysed the data, and drafted and revised the paper. DY-YT provided technical input on lens design, revised the paper. YYT implemented the trial, input data and provide input in statistical analysis. CHT designed data collection tools, monitored data collection for the whole trial, wrote the statistical analysis plan, and revised the paper.

Funding The study was supported by grants of RGC GRF (B-Q04G) and Niche Areas Fund (J-BB7P) from The Hong Kong Polytechnic University.

Competing interests None.

Patient consent Obtained.

Ethics approval Human Subjects Ethics Subcommittee of the Hong Kong Polytechnic University.

Provenance and peer review Not commissioned; externally peer reviewed.

Data sharing statement Visual functions measurement including Visual acuity, contrast sensitivity, external ocular health conditions, binocular status are also available for the 24 months of follow-up.

Commercial relationship None. A patent 'Method of Optical Treatment' in USA (patent no. 7506983) and Australia (patent no. 2005289302) were issued on 24
Mar 2009 and 29 July 2010, respectively. The study was registered at ClinicalTrials. gov, number NCT00919334.

Open Access This is an Open Access article distributed in accordance with the Creative Commons Attribution Non Commercial (CC BY-NC 3.0) license, which permits others to distribute, remix, adapt, build upon this work non-commercially, and license their derivative works on different terms, provided the original work is properly cited and the use is non-commercial. See: http://creativecommons.org/ licenses/by-nc/3.0/

\section{REFERENCES}

1 Lam CS, Edwards M, Millodot M, et al. A 2-year longitudinal study of myopia progression and optical component changes among Hong Kong schoolchildren. Optom Vis Sci 1999:76:370-80.

2 Lam CS, Goldschmidt E, Edwards MH. Prevalence of myopia in local and international schools in Hong Kong. Optom Vis Sci 2004;81:317-22.

3 Lim MC, Gazzard G, Sim EL, et al. Direct costs of myopia in Singapore. Eye 2009:23:1086-9.

4 Vongphanit J, Mitchell P, Wang JJ. Prevalence and progression of myopic retinopathy in an older population. Ophthalmology 2002;109:704-11.

5 Xu L, Wang Y, Wang S, et al. High myopia and glaucoma susceptibility the Beijing Eye Study. Ophthalmology 2007;114:216-20.

6 Edwards MH, Li RW, Lam CS, et al. The Hong Kong progressive lens myopia control study: study design and main findings. Invest Ophthalmol Vis Sci 2002:43:2852-8

7 Gwiazda J, Hyman L, Hussein $M$, et al. A randomized clinical trial of progressive addition lenses versus single vision lenses on the progression of myopia in children. Invest Ophthalmol Vis Sci 2003;44:1492-500.

8 Hasebe $S$, Ohtsuki H, Nonaka T, et al. Effect of progressive addition lenses on myopia progression in Japanese children: a prospective, randomized double-masked, crossover trial. Invest Ophthalmol Vis Sci 2008;49:2781-9.

9 Yang Z, Lan W, Ge J, et al. The effectiveness of progressive addition lenses on the progression of myopia in Chinese children. Ophthalmic Physiol Opt 2009;29:41-8.

10 Correction of Myopia Evaluation Trial 2 Study Group for the Pediatric Eye Disease Investigator Group. Progressive-addition lenses versus single-vision lenses for slowing progression of myopia in children with high accommodative lag and near esophoria. Invest Ophthalmol Vis Sci 2011;52:2749-57.

11 Berntsen DA, Sinnott LT, Mutti DO, et al. A randomized trial using progressive addition lenses to evaluate theories of myopia progression in children with a high lag of accommodation. Invest Ophthalmol Vis Sci 2012;53:640-9.

12 Cheng D, Schmid KL, Woo GC, et al. Randomized trial of effect of bifocal and prismatic bifocal spectacles on myopic progression: two-year results. Arch Ophthalmol 2010;128:12-19.

13 Cho P, Cheung SW. Retardation of myopia in Orthokeratology (ROMIO) study: a 2-year randomized clinical trial. Invest Ophthalmol Vis Sci 2012;53:7077-85.

14 Siatkowski RM, Cotter SA, Crockett RS, et al. Two-year multicenter, randomized, double-masked, placebo-controlled, parallel safety and efficacy study of $2 \%$ pirenzepine ophthalmic gel in children with myopia. J AAPOS 2008;12:332-9.

15 Wallman J, Winawer J. Homeostasis of eye growth and the question of myopia. Neuron 2004:43:447-68.

16 Liu Y, Wildsoet C. The effect of two-zone concentric bifocal spectacle lenses on refractive error development and eye growth in young chicks. Invest Ophthalmol Vis Sci 2011;22:1078-86.

17 Tse DY, To CH. Graded competing regional myopic and hyperopic defocus produce summated emmetropization set points in chick. Invest Ophthalmol Vis Sci 2011;52:8056-62.

18 Altman DG. Better reporting of randomised controlled trials: the CONSORT statement. BMJ 1996:313:570-1.

19 Lo P, Tse DY, Lam CSY, et al. Alternating monvision contact lens wear arrested fast progressing myopia. Clinical \&Refractive Optometry 2010;21:38.

20 Zhu X, Wallman J. 2009. Temporal properties of compensation for positive and negative spectacle lenses in chicks. Invest Ophthalmol Vis Sci 2009;50:37-46.

21 Sankaridurg P, Holden B, Smith E III, et al Decrease in rate of myopia progression with a contact lens designed to reduce relative peripheral hyperopia: one-year results. Invest Ophthalmol Vis Sci 2011;52:9362-7.

22 Anstice NS, Phillips JR. Effect of dual-focus soft contact lens wear on axial myopia progression in children. Ophthalmology 2011;118:1152-61.

23 Atchison DA, Pritchard N, Schmid KL, et al. Shape of the retinal surface in emmetropia and myopia. Invest Ophthalmol Vis Sci 2005;46:2698-707. 